\title{
Antimanic Efficacy of a Novel Kv3 Potassium Channel Modulator
}

\author{
Puja K Parekh',5, Michelle M Sidor ${ }^{1,5}$, Andrea Gillman', Darius Becker-Krail', Letizia Bettelini ${ }^{2}$, \\ Roberto Arban ${ }^{3}$, Giuseppe S Alvaro ${ }^{4}$, Erika Zambello ${ }^{2}$, Chiara Mutinelli ${ }^{2}$, Yanhua Huang', Charles H Large ${ }^{4}$ \\ and Colleen A McClung*,I
}

'Department of Psychiatry, University of Pittsburgh Medical Center, Pittsburgh, PA, USA; ${ }^{2}$ Aptuit, Verona, Italy; ${ }^{3}$ Boehringer Ingelheim, Biberach, Germany; ${ }^{4}$ Autifony Therapeutics, Imperial College Incubator, London, UK

\begin{abstract}
Kv3.I and Kv3.2 voltage-gated potassium channels are expressed on parvalbumin-positive GABAergic interneurons in corticolimbic brain regions and contribute to high-frequency neural firing. The channels are also expressed on GABAergic neurons of the basal ganglia, substantia nigra, and ventral tegmental area (VTA) where they regulate firing patterns critical for movement control, reward, and motivation. Modulation of Kv3.I and Kv3.2 channels may therefore have potential in the treatment of disorders in which these systems have been implicated, such as bipolar disorder. Following the recent development of a potassium channel modulator, AUTI—an imidazolidinedione compound that specifically increases currents mediated by Kv3.I and Kv3.2 channels in recombinant systems-we report that the compound is able to reverse 'manic-like' behavior in two mouse models: amphetamine-induced hyperactivity and Clock $\Delta$ I 9 mutants. AUTI completely prevented amphetamine-induced hyperactivity in a dose-dependent manner, similar to the atypical antipsychotic, clozapine. Similar efficacy was observed in Kv3.2 knockout mice. In contrast, AUTI was unable to prevent amphetamineinduced hyperactivity in mice lacking Kv3.I channels. Notably, Kv3.I-null mice displayed baseline hyperlocomotion, reduced anxiety-like behavior, and antidepressant-like behavior. In Clock 19 mice, AUTI reversed hyperactivity. Furthermore, AUTI application modulated firing frequency and action potential properties of Clock $19 \mathrm{VTA}$ dopamine neurons potentially through network effects. Kv3.I protein levels in the VTA of Clock $\Delta 19$ and WT mice were unaltered by acute AUTI treatment. Taken together, these results suggest that the modulation of Kv3.I channels may provide a novel approach to the treatment of bipolar mania.
\end{abstract}

Neuropsychopharmacology (2018) 43, 435-444; doi:I0.1038/npp.2017.155; published online 27 September 2017

\section{INTRODUCTION}

Treatment of bipolar mania is currently based on a mixture of serendipitously discovered drugs, including the antipsychotic drug olanzapine, anticonvulsants such as valproate and lamotrigine, and lithium (Beaulieu and Caron, 2008; Geddes and Miklowitz, 2013; Tohen and Vieta, 2009). With the possible exception of lithium, these drugs primarily treat the symptoms and not necessarily the underlying disease pathology. Furthermore, many pharmacological treatment options in use today are associated with significant safety and tolerability issues that ultimately limit their utility. There is a desperate need for novel approaches that target the primary pathophysiological mechanisms thought to underlie bipolar disorder.

Some, if not all, symptoms of bipolar mania may be caused by an imbalance in the reward and motor circuits of the

\footnotetext{
*Correspondence: Dr CA McClung, Department of Psychiatry, University of Pittsburgh, 450 Technology Drive, Pittsburgh, PA I5219, USA, Tel: 4I2 624 5547, Fax: 412624 5280,

E-mail: mcclungca@upmc.edu

${ }^{5}$ These two authors contributed equally to this work.

Received 8 February 20 I7; revised 12 July 20 I7; accepted I 4 July 20 I7; accepted article preview online 31 August 2017
}

mesolimbic system and basal ganglia (Caseras et al, 2013; Phillips and Swartz, 2014; Salvadore et al, 2010). Behavioral abnormalities similar to symptoms of bipolar mania can be induced in mice by interventions that alter activity of the nigrostriatal and mesolimbic dopamine pathways. Two such approaches involve acute amphetamine administration (Lyon, 1991; Martinowich et al, 2009) and genetic mutation of the Clock gene in mice (McClung et al, 2005; Mukherjee et al, 2010; Roybal et al, 2007). Previous studies found that the Clock $\Delta 19$ mice have an increase in dopamine cell firing and bursting in the ventral tegmental area (VTA) that appear to underlie many of their manic-like phenotypes, including hyperactivity (Coque et al, 2011; McClung et al, 2005; Roybal et al, 2007). Psychiatrists have used antipsychotic interventions to reduce the 'over-activity' of the dopamine system by inhibiting postsynaptic dopamine receptors. Although this approach is helpful to some patients, it necessarily leads to significant adverse effects. An alternative approach may be to consider the activity of GABAergic neurons of the basal ganglia and mesolimbic system that control movement and reward.

Voltage-gated potassium channels (Kv) are a subfamily of potassium channels that are integral for maintaining membrane potential and shaping action potential generation 
(Gonzalez et al, 2012). Kv3.1 channels have been implicated in the maintenance of high-frequency firing of GABAergic output neurons in the globus pallidus (Hernandez-Pineda et al, 1999) and substantia nigra (Ding et al, 2011), areas critical to maintaining inhibitory control over motor output. Although function of Kv3 channels in the mesolimbic system has not yet been demonstrated, distribution studies confirm the presence of Kv3.1 channels in the VTA and striatum (Lenz et al, 1994), and hence an analogous mechanism of control over reward and motivation could be proposed.

Activation of Kv3.1 channels may help enhance the fast firing of GABAergic neurons in these systems to re-establish the balance of inhibitory control in patients with bipolar disorder without resorting to blockade of the dopamine system. To this end, we have investigated the efficacy of a novel class of drug that modulates Kv3.1 channels (RosatoSiri et al, 2015) in two models of mania-like hyperactivity associated with imbalance of the mesolimbic system in mice: acute amphetamine treatment and the Clock $\Delta 19$ genetic mutation.

\section{MATERIALS AND METHODS}

\section{Animals}

Male Clock $\Delta 19$ mutant mice were created by $N$-ethyl- $N$ nitrosourea mutagenesis that produces a dominant-negative CLOCK protein defective in transcriptional activity (King et al, 1997) and were obtained from J Takahashi (UT Southwestern). For all behavioral experiments using Clock $\Delta 19$ mutants, adult male mutants (Clock/Clock) were compared with wild-type $(+/+)$ littermate controls (1012 weeks) on a mixed $\mathrm{BALBc} \times \mathrm{C} 57 \mathrm{BL} / 6$ background. Clock $\Delta 19$ mice (4-6 weeks) were used for electrophysiological experiments. Kv3.1-null (Kv3.1-/-) male mice (Ho et al, 1997) on a mixed C57BL/6×129 background were obtained from R Joho (UT Southwestern) and het-het breeding was used to obtain both nulls and WT littermate controls; Kv3.2-null (Kv3.2-/-) male mice were obtained from B Rudy (New York University). CD1 outbred male mice (8-12 weeks) were purchased from Jackson Labs. All mice were maintained on a $12 / 12 \mathrm{~h}$ light/dark cycle (lights on/off at $0700 / 1900 \mathrm{~h}$ ) with food and water provided ad libitum. Mice were housed 2-4 per cage. All animal use was conducted in accordance with the National Institute of Health guidelines and approved by the institutional animal care and use committees of the University of Pittsburgh and UT Southwestern Medical Center.

\section{Drug Preparation}

AUT1 (structure: (5R)-5-ethyl-3-(6-\{[4-methyl-3-(methyloxy)phenyl] oxy $\}-3$-pyridinyl)-2,4-imidazolidinedione; Autifony Therapeutics, UK) was administered through oral gavage and prepared fresh in vehicle (AUT1-vehicle) consisting of $0.1 \%$ Tween 20, 0.5\% HPMC K15EP (Colorcon), and $12.5 \%$ Captisol in bacteriostatic saline. Freshly prepared AUT1 was administered 30 min before behavioral testing. D-Amphetamine ( $2 \mathrm{mg} / \mathrm{kg}$, i.p. or $4 \mathrm{mg} / \mathrm{kg}$, i.p.) and clozapine $(3 \mathrm{mg} / \mathrm{kg}$, i.p.) (Sigma, St Louis, MO) were prepared fresh in saline. All drugs were dosed at $10 \mathrm{ml} / \mathrm{kg}$.

\section{Behavioral Assays}

Mood-related behavioral assays were performed in a cohort of Kv3.1-null mice with at least 1 week between tests. Behavioral testing was conducted during the light cycle and mice were habituated to the environment for at least $30 \mathrm{~min}$. Assay details are provided in the Supplementary Materials and Methods.

\section{VTA Slice Preparation}

Clock $\Delta 19$ mutant mice were anesthetized rapidly with isoflurane inhalation and decapitated. Brains were removed into ice-cold oxygenated $\left(95 \% \mathrm{O}_{2} / 5 \% \mathrm{CO}_{2}\right)$ modified aCSF. VTA-containing horizontal slices $(200 \mu \mathrm{m})$ were sectioned with a vibratome (VT1200S; Leica, Wetzlar, Germany) and incubated for $12 \mathrm{~min}$ at $37^{\circ} \mathrm{C}$ in the same solution. Slices were then transferred to room temperature holding aCSF until recording. Further details are provided in Supplementary Materials and Methods.

\section{Whole-Cell Patch-Clamp Recordings}

Slices were viewed by differential interference contrast (DIC) optics (Leica) and the VTA was localized medial to the optic tract. Recordings were made under $\times 40$ objective. Slices were maintained at $30-32{ }^{\circ} \mathrm{C}$ in oxygenated aCSF. Giga-Ohm seal was achieved and spontaneous sodium currents recorded in cell-attached mode to differentiate dopamine and nondopamine neurons (Johnson and North, 1992). Cells were voltage clamped at $-65 \mathrm{mV}$ and a hyperpolarizing voltage step protocol was applied $(0 \mathrm{mV}$ to $-100 \mathrm{mV})$ to detect the presence of ' $h$ ' current for further identification of neurons (Margolis et al, 2006). For recordings, cells were current clamped and action potential (AP) firing was recorded in response to increasing current steps ( -80 to $200 \mathrm{pA})$ in the presence of DMSO (0.1\%) or $10 \mu \mathrm{M}$ AUT1 (dissolved in $0.1 \%$ DMSO; $30+$ min bath incubation), a dose previously confirmed to modulate Kv3.1 channels (Rosato-Siri et al, 2015). AP properties were analyzed using pClamp10 software (Molecular Devices, Sunnyvale, CA). Additional details can be found in Supplementary Materials and Methods.

\section{Immunohistochemistry}

Free-floating tissue sections underwent antigen retrieval and were permeabilized and then blocked at RT and incubated for $48 \mathrm{~h}$ with rabbit anti-Kv3.1b antibody (Sigma P9732). Following primary antibody incubation, sections were washed and incubated at RT with a goat anti-rabbit HRP conjugated antibody, followed by several washes. Signal was amplified by incubating sections in tyramide working solution. Sections were mounted and cover-slipped for fluorescence imaging. Details are contained within Supplementary Materials and Methods.

\section{Western Blotting}

Briefly, mice were rapidly killed and VTA tissue was dissected and immediately frozen. Tissue samples were homogenized by sonication for protein extraction in phosphatase and protease inhibitor containing buffer. 
a
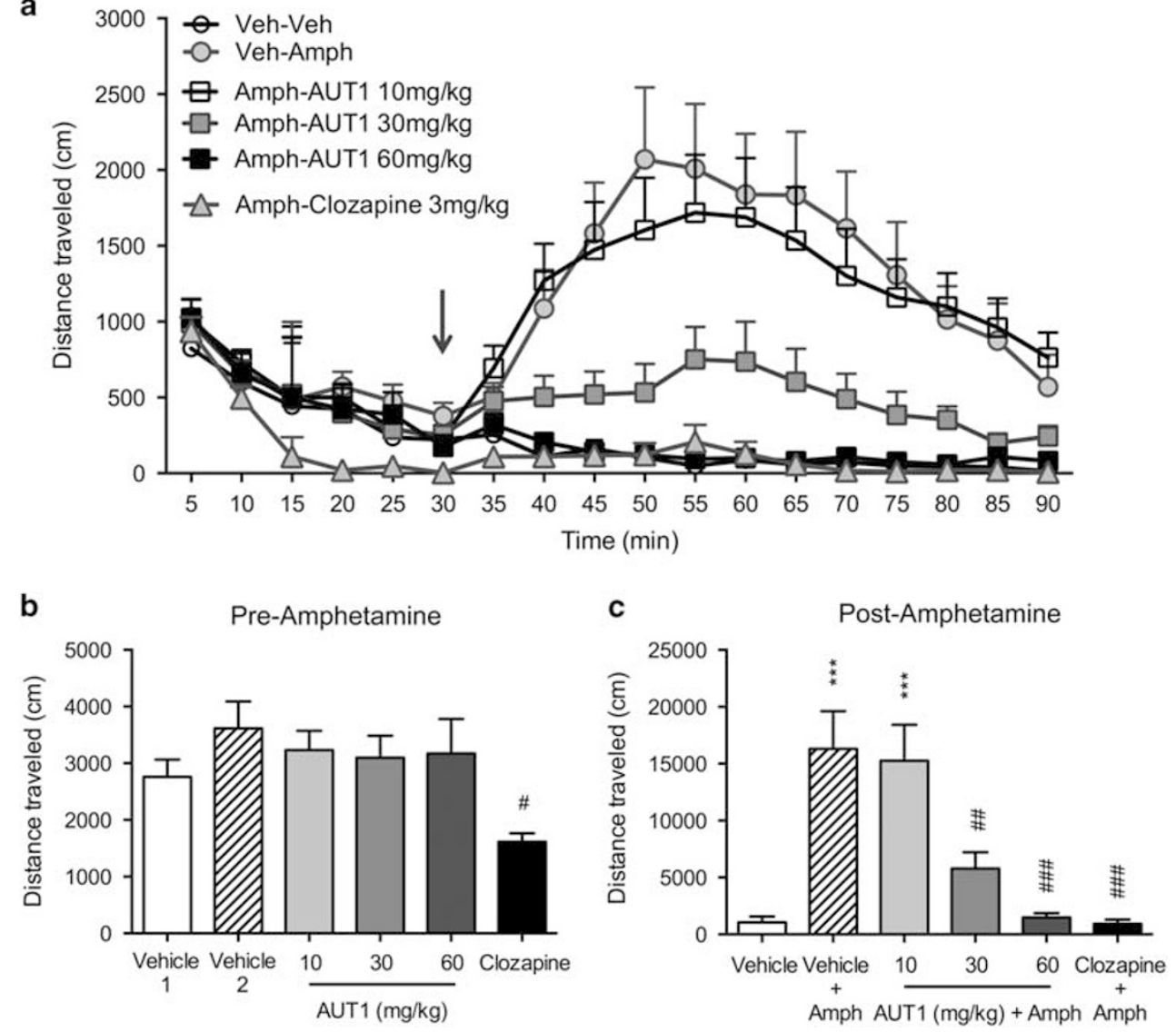

Figure I A Kv channel modulator (AUTI) prevents amphetamine-induced hyperactivity. (a) CDI mice were pretreated with AUTI (I0, 30, or 60 mg/kg) or AUTI-vehicle $30 \mathrm{~min}$ before a single injection of $2 \mathrm{mg} / \mathrm{kg}$ amphetamine (indicated by arrow). Locomotor behavior was assessed both before (b) and after (c) amphetamine injection. Clozapine was administered as a positive control. (a) Time course of locomotor activity following AUTI administration at T= 0 min and after amphetamine injection at $T=30 \mathrm{~min}$. (b) There was a significant difference in locomotor activity across pretreatment groups, with a specific reduction in locomotor activity within the clozapine group before amphetamine injection. Note that two vehicle groups are depicted to dissociate groups that subsequently received a second dose of a vehicle (vehicle group I: vehicle+vehicle) vs a dose of amphetamine (vehicle group 2: vehicle+Amph). Importantly, AUTI had no effect on locomotor activity before amphetamine injection. (c) As expected, amphetamine injection resulted in a significant increase in activity in vehicle pretreated CDI mice and in mice that were pretreated with a low dose of AUTI (I0 mg/kg). Locomotor activity following amphetamine injection was significantly lower in mice that were pretreated with higher doses of AUTI (30 and $60 \mathrm{mg} / \mathrm{kg}$ ) relative to vehicle pretreated mice, ie, locomotor activity following amphetamine injection in AUTI pretreated mice was not significantly different than mice that did not receive amphetamine (saline injection). The highest dose of AUTI was as effective as clozapine pretreatment at preventing amphetamine-induced hyperactivity (clozapine vs vehicle+Amph). Vehicle group $=$ AUTI vehicle pretreatment + saline injection. Vehicle + Amph $=$ AUTI-vehicle pretreatment+amphetamine. Treatment group vs vehicle $* * * *$ $<0.00$ I; treatment group

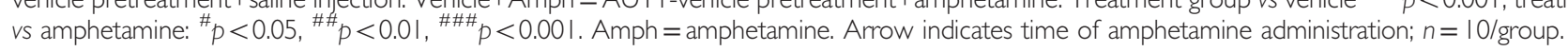

Protein concentration was determined by DC assay. Normalized samples were loaded onto precast gels. Proteins were transferred overnight to PVDF membranes. Membranes were rewet and incubated for $24 \mathrm{~h}$ at RT with the primary antibody anti-Kv3.1b and mouse anti-GAPDH. The following day, blots were washed and incubated with infrared (IR) Dye 680-conjugated goat anti-mouse antibody. Blots were washed once again and scanned using the Odyssey Infrared Imaging System. Values are expressed as a ratio to the corresponding GAPDH integrated intensity. Details are contained in the Supplementary Materials and Methods section.

\section{Pharmacokinetics}

Blood aliquots were collected into micronic tubes $(70 \mu \mathrm{l}$ blood $+130 \mu$ l water with HEPES $0.1 \mathrm{~N}$ ), vortexed, and stored at $4{ }^{\circ} \mathrm{C}$ before the assay. Samples were vortexed and centrifuged at 3000 r.p.m. for $10 \mathrm{~min}$ and diluted into 96well plates for the assay ( $80 \mu \mathrm{l}$ water $+100 \mu \mathrm{l}$ supernatant). Brains were homogenized with $4.3 \mathrm{vol}$ di $\mathrm{MeOH} 50 \%$ and collected into tubes $(200 \mu \mathrm{l})$. Homogenates were then vortexed and centrifuged at 3000 r.p.m. for $10 \mathrm{~min}$ and the aliquots of the supernatant transferred to 96-well plates. High-performance liquid chromatographic (HPLC) assays using mass spectrometric detection (LC-MS/MS with UV) for the determination of AUT1 were developed and validated to identify the compound in brain and blood matrices.

\section{Statistical Analysis}

Data were analyzed using an unpaired Student's $t$-test, whereas comparisons of three or more group means were conducted using an analysis of variance (ANOVA) followed by a Bonferroni or Dunnett post hoc test for multiple comparisons. Analyses over time were conducted using a 

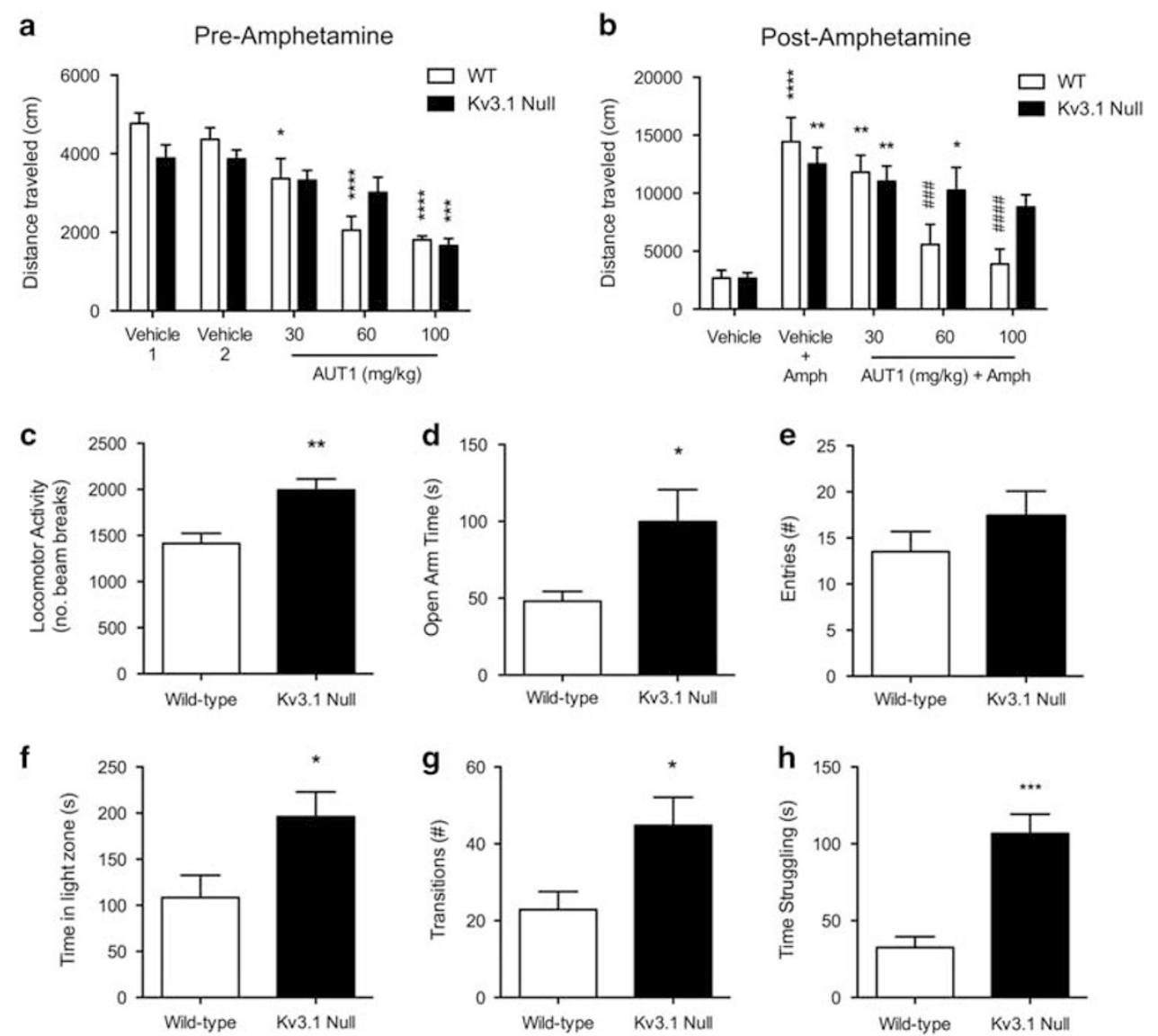

Figure 2 AUTI does not attenuate amphetamine-induced hyperactivity in Kv3. I-null mice and these mice exhibit manic-related behaviors. (a) Cohorts of mice were pretreated with AUTI (30,60, or $100 \mathrm{mg} / \mathrm{kg}$, i.p.) or AUT-vehicle before amphetamine injection (4 mg/kg, i.p.) at T=30 min. Bonferroni post hoc analyses revealed that wild-type (WT) mice decreased locomotor activity in response to AUT administration in a dose-dependent manner relative to vehicletreated WT mice. In Kv3. I -null mice, only AUTI at the highest dose of $100 \mathrm{mg} / \mathrm{kg}$ significantly reduced activity relative to vehicle-treated Kv3.I mice. Note that two vehicle groups are depicted to dissociate groups that subsequently received a second dose of a vehicle (vehicle group I: vehicle+vehicle) vs a dose of amphetamine (vehicle group 2: vehicle+Amph). (b) Bonferroni post hoc analyses revealed that amphetamine injection led to a significant increase in locomotor activity in both vehicle pretreated WT and Kv3.I-null mice and in mice pretreated with the lower $30 \mathrm{mg} / \mathrm{kg}$ dose of AUTI. AUTI administered at 60 and $100 \mathrm{mg} / \mathrm{kg}$, however, prevented amphetamine-induced hyperactivity in WT mice, leading to a significant reduction in locomotor behavior relative to vehicle pretreated mice administered amphetamine (WT AUTI vs Amph). In contrast, AUTI was not effective at preventing amphetamine-induced hyperactivity in Kv3. I-null mice, with significant increases in locomotion observed following amphetamine injection at $30 \mathrm{mg} / \mathrm{kg}$ (Kv3.I AUTI vs vehicle) and $60 \mathrm{mg} / \mathrm{kg}$ but not

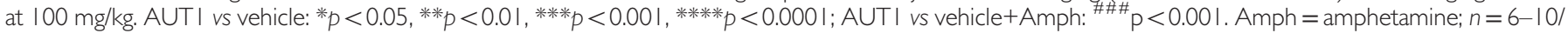
group. (c) Kv3. I-null mice exhibited a significant increase in total locomotor activity over a I h test in novel locomotor chambers. Anxiety-like behaviors were decreased in Kv3. I-null mice as demonstrated by significant increases in (d) time spent exploring the open arms of the elevated plus maze (no difference in entries into open arm (e)) and in (f, g) time spent in, and transitions into, the light chamber of the light/dark test. (h) Furthermore, Kv3.I mice exhibited a significant increase in time spent struggling in the forced swim test. WT vs Kv3.I: $* p<0.05$, *** $p<0.01$, **** $p<0.00$ I; $n=8 /$ genotype.

two-way repeated measures ANOVA followed by Bonferroni's post hoc test to control for multiple comparisons. In some instances, interactions that reached significance or trended toward significance were followed up with post hoc Student's $t$-tests and are indicated in the figure legends. Analyses were conducted using the GraphPad Prism 5 statistical software for Windows. Data are presented as mean \pm SEM with a two-tailed $p$-value of $\leqslant 0.05$ considered statistically significant.

\section{RESULTS}

\section{AUT1 Attenuates Amphetamine-Induced Hyperactivity: Importance of Kv3.1 Channels}

The efficacy of AUT1 was first assessed in the amphetamineinduced hyperactivity model in the outbred CD1 mouse strain (Figure 1). AUT1, administered 30 min before a single dose of amphetamine, was effective in preventing amphetamine-induced hyperactivity in a dose-dependent manner (Figures 1a and c). One-way ANOVA revealed a significant difference between pretreatment groups $\left(\mathrm{F}_{5,57}=2.96, p=0.02\right)$. Both 30 and $60 \mathrm{mg} / \mathrm{kg}$ doses were effective in attenuating hyperactivity, whereas no significant effect was found with a $10 \mathrm{mg} / \mathrm{kg}$ AUT1 dose. Significant group differences were found in locomotor activity during the 60 min following amphetamine injection $\left(F_{(5,54)}=13.17\right.$, $p<0.0001$; Figure 1c). Importantly, the higher $(60 \mathrm{mg} / \mathrm{kg})$ AUT1 dose was as effective as clozapine, an antipsychotic with demonstrated anti-manic efficacy (Tohen and Vieta, 2009), at preventing hyperactivity. Pharmacokinetic analyses were conducted to measure the systemic exposure and brain penetration of differing doses of AUT1 (10,30, and $60 \mathrm{mg} /$ $\mathrm{kg}$ ) in male CD1 mice at $30 \mathrm{~min}$ (blood concentration) and 
$90 \mathrm{~min}$ (blood and brain concentration measured following locomotor testing) after administration (see Supplementary Table S1). Overall, brain penetration was high and consistent among the doses. The mean brain-to-blood concentration ratio for AUT1 was ca. 1.6. Importantly, sufficient brain penetration was observed at all doses tested and was concurrent with behavioral effects seen during efficacy testing. Free brain concentrations at $90 \mathrm{~min}$ ranged from 0.1 to $2.1 \mu \mathrm{M}$ at $90 \mathrm{~min}$ and are estimated to have been up to 2-fold higher at $30 \mathrm{~min}$. AUT1 positively modulated recombinant Kv3.1 and Kv3.2 channels with an EC50 of $5 \mu \mathrm{M}$ (Rosato-Siri et al, 2015); thus the achieved free brain concentrations would be expected to modulate these channels by $10-20 \%$.

To test the specificity of this effect to Kv3.1 channels, separate cohorts of Kv3.1-null mice and their WT littermates were administered three different doses of AUT1 (or vehicle) $30 \mathrm{~min}$ before a single injection of amphetamine or vehicle (Figure 2 and Supplementary Figure S1). Both WT and Kv3.1-null mice exhibited the expected increase in locomotor activity following a single amphetamine injection (Figure 2b). WT mice, however, that received AUT1 before amphetamine, exhibited attenuation in amphetamineinduced hyperactivity with the effects most notable at the 60 and $100 \mathrm{mg} / \mathrm{kg}$ doses. Two-way ANOVA revealed a significant main effect of treatment on locomotor activity $\left(\mathrm{F}_{(4,67)}=22.37, \quad p<0.0001\right)$ and a genotype $\times$ treatment interaction $\left(\mathrm{F}_{(4,67)}=2.28, p=0.07\right.$; Figure $\left.2 \mathrm{~b}\right)$. At the highest dose of $100 \mathrm{mg} / \mathrm{kg}$, AUT1 significantly decreased locomotor activity in both WT and Kv3.1-null mice before amphetamine injection, possibly indicating a nonspecific sedative effect at this dose (Figure 2a). AUT1, however, was not effective at reducing amphetamine-induced hyperactivity in mice lacking Kv3.1 channels, even at these high doses (Figure 2b and Supplementary Figure S1), arguing against a purely sedative effect. This suggests that functional Kv3.1 channels are required for the effects of AUT1 on amphetamine-induced hyperactivity. Notably, this was confirmed by repeating the experiment using Kv3.2 knockout mice where AUT1 was as effective at preventing hyperactivity as in WT mice $\left(\mathrm{F}_{(2,24)}=12.73, p=0.0002\right.$; Supplementary Figure S2). Collectively, this suggests that Kv3.1 channels (and not Kv3.2) are necessary for AUT1 mechanism of action in this model.

\section{Kv3.1-Null Mice Exhibit Manic-Like Behaviors}

To further establish an association between Kv3.1 channels and mood- and activity-related behaviors, mice lacking Kv3.1 channels were tested in a behavioral battery to assess features of manic-like behavior including exploratory, anxiety-, and depressive-like behaviors. Kv3.1-null mice exhibited a hyperactive phenotype during a $1 \mathrm{~h}$ locomotor test $\left(t_{12}=3.55, p<0.01\right.$; Figure $\left.2 \mathrm{c}\right)$. Kv3.1-null mice also
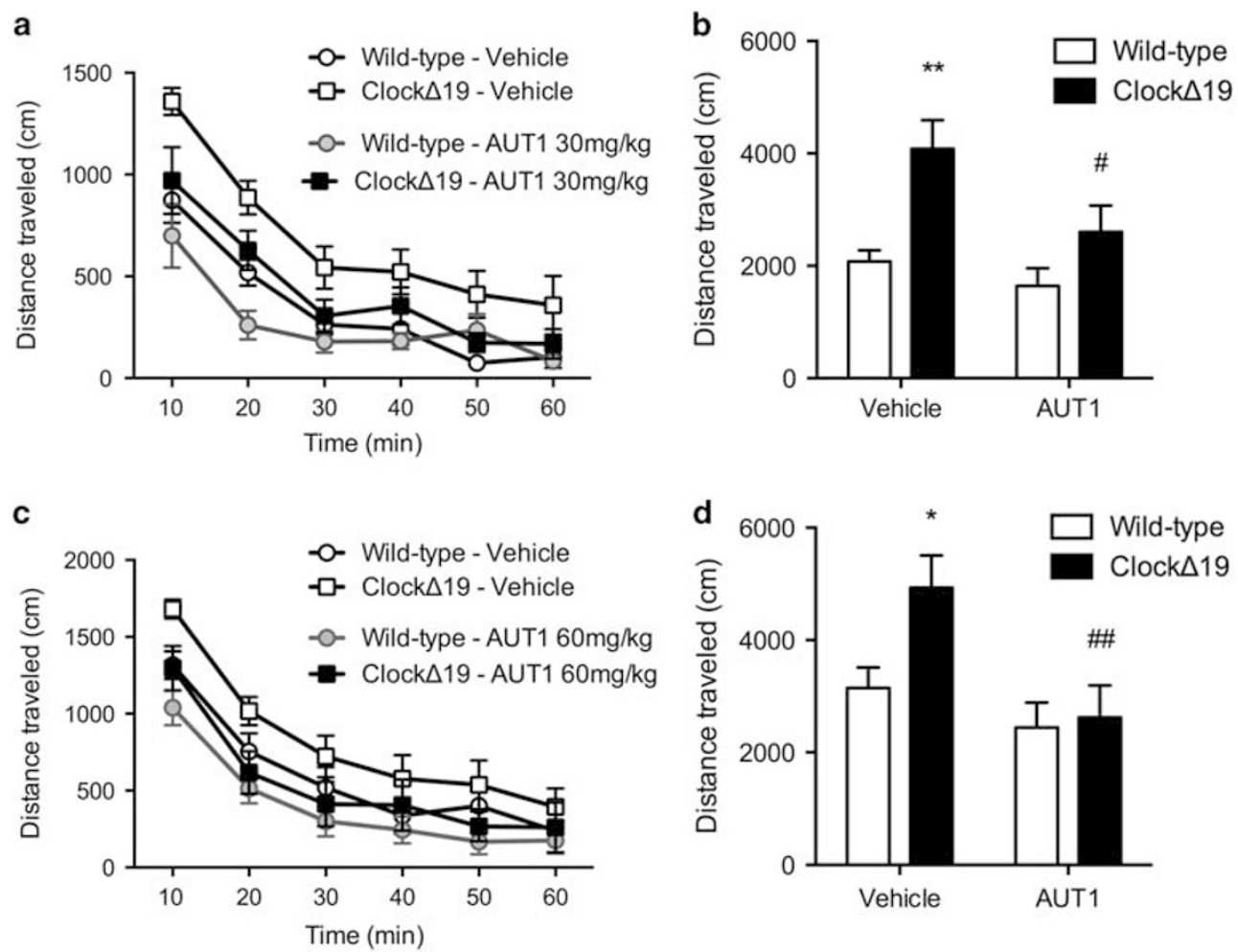

Figure 3 AUTI reverses hyperactivity in the Clock 19 mutant mouse model of mania. (a, c) Time course of locomotor activity in wild-type (WT) and Clock $\Delta 19$ administered (a, b) $30 \mathrm{mg} / \mathrm{kg}$ or (c, d) $60 \mathrm{mg} / \mathrm{kg}$ dose of AUTI or vehicle (AUTI -vehicle) at T = $0 \mathrm{~min}$. (b). As expected, Bonferroni post hoc analyses revealed that vehicle-treated Clock $\Delta 19$ mice exhibited a significant increase in locomotor activity relative to WT mice. Clock $\Delta 19$ mice administered $30 \mathrm{mg} / \mathrm{kg}$ AUTI exhibited a significant reduction in locomotor activity compared with vehicle treatment. (d) The ability of AUTI to reduce hyperactivity in Clock $\Delta$ I 9 mutants was additionally tested at a $60 \mathrm{mg} / \mathrm{kg}$ dose. Hyperactivity was seen in vehicle-treated Clock $\Delta 19 \mathrm{vs}$ WT and a complete reversal of this phenotype with $60 \mathrm{mg} / \mathrm{kg}$ AUTI administration (Clock 19 AUTI vs vehicle). Genotype effects: ${ }^{*} p<0.05$, *** $p<0.0$ I; treatment effects: ${ }^{*} p<0.05,{ }^{\# \#} p<0.0$ I; $n=7-8$ I genotype. 

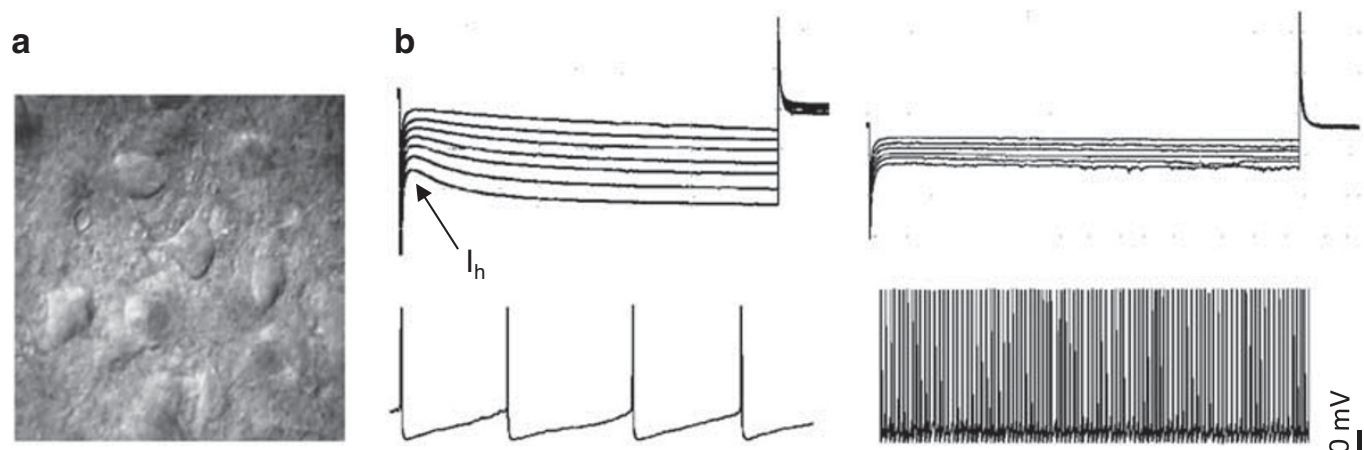

$>20 \mathrm{~Hz}$

छे

1-3 Hz

C

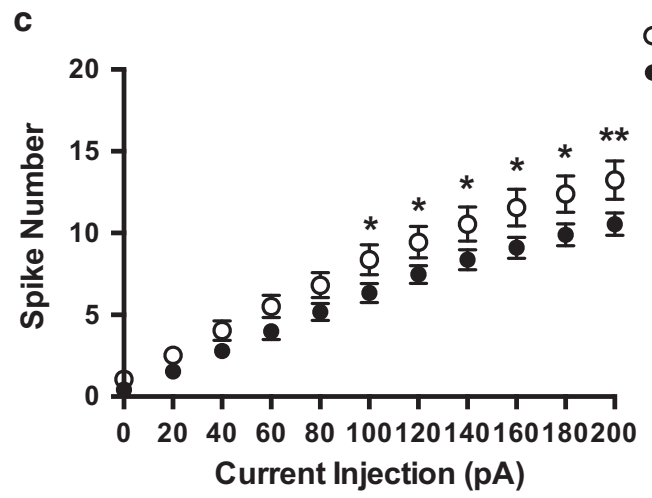

- DMSO

- AUT1 $(10 \mu \mathrm{M})$

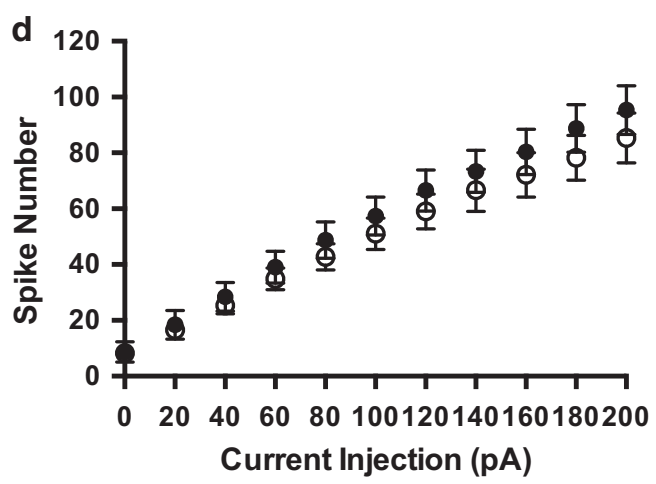

Figure 4 The firing rate of Clock 19 VTA dopamine neurons is attenuated by AUTI. (a) Micrograph of VTA dopamine neurons in a brain slice from Clock $\Delta 19$ mutant mice. (b) DA neurons exhibit a characteristic $I_{h}$-mediated 'sag' response to hyperpolarizing voltage steps and spontaneous activity in the range of $\mathrm{I}-3 \mathrm{~Hz}$ (left), but putative GABAergic neurons in the VTA lack $\mathrm{I}_{\mathrm{h}}$ current and fire at a rate higher than $20 \mathrm{~Hz}$ (right). (c) AUTI reduced the firing of DA neurons compared with DMSO specifically at higher current steps. (d) AUTI application did not significantly alter the firing of GABAergic cells in a small sample group; $n=14-19$ DA cells/treatment; $n=6$ GABA cells/treatment; $* p<0.05$, $* * * 0.01$.

exhibited an increase in exploration of the open arms of the elevated plus maze (Figures $2 \mathrm{~d}$ and $\mathrm{e}$ ), independent of overall locomotor activity as indicated by similar numbers of closed arm entries $\left(t_{14}=0.025, \quad p=0.980 ; \quad\right.$ Supplementary Figure S3a). Furthermore, Kv3.1-null mice exhibited greater activity in the light chamber of the light/dark test (Figures $2 \mathrm{f}$ and $\mathrm{g}$ ), indicating an overall decrease in anxiety-like behaviors (time: $t_{12}=2.43, p=0.032$; transitions: $t_{13}=2.42$, $p=0.031$ ). These measures were also not confounded by significant differences in overall activity in the light zone $\left(t_{14}=1.34, p=0.201\right)$, dark zone $\left(t_{14}=1.27, p=0.226\right)$, or total activity $\left(t_{14}=1.91, p=0.077\right)$ (Supplementary Figures S3b-d). In the forced swim test, Kv3.1-null mice exhibited antidepressant-like behavior as evidenced by increased time spent struggling relative to WT littermate controls $\left(t_{14}=5.11\right.$, $p=0.0002$; Figure $2 \mathrm{~h}$ ).

\section{Effects of AUT1 on Hyperactivity in the Clocks19 Mutant Mouse Model of Mania}

The ability of AUT1 to attenuate hyperactivity was additionally tested in the well-validated Clock $\Delta 19$ mutant mouse model of mania (Roybal et al, 2007). As expected, vehicle-treated Clock $\Delta 19$ mice exhibited hyperactivity compared with WT littermate controls throughout the duration of locomotor testing $(p<0.01$; Figure 3$)$. Clock $\Delta 19$ mutant mice that received acute administration of AUT1, however, exhibited a reduction in locomotor activity at both a $30 \mathrm{mg} /$ $\operatorname{kg}\left(\mathrm{F}_{(1,27)}=14.67, p=0.0007\right.$, genotype effect; $\mathrm{F}_{(1,27)}=6.11$, 
a
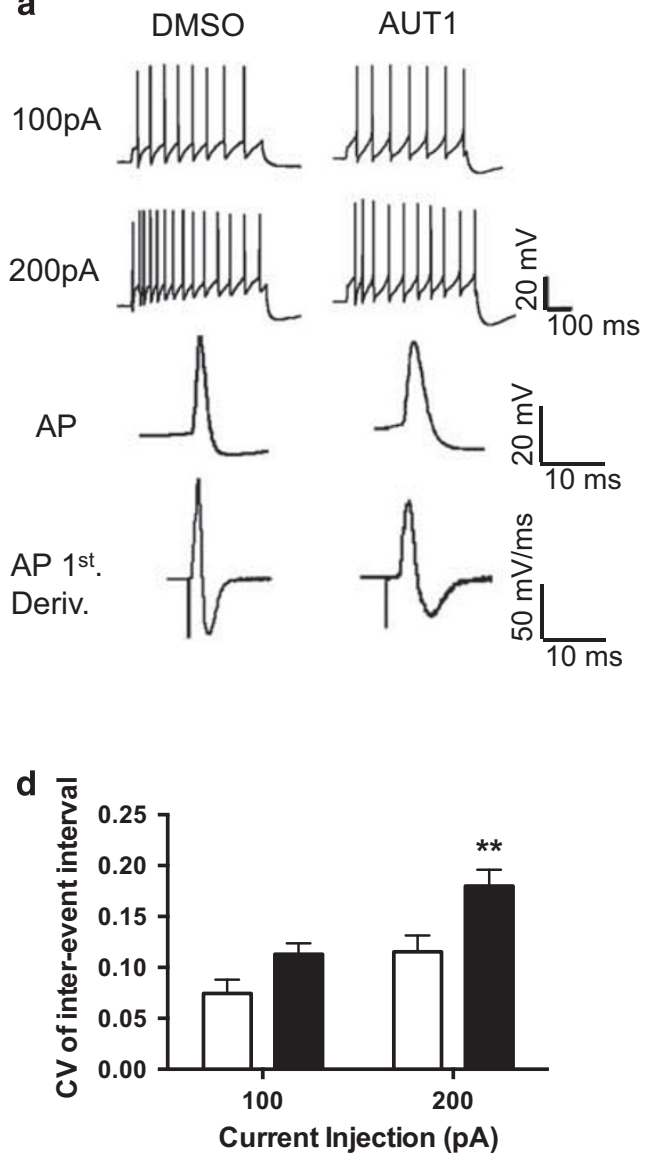

f

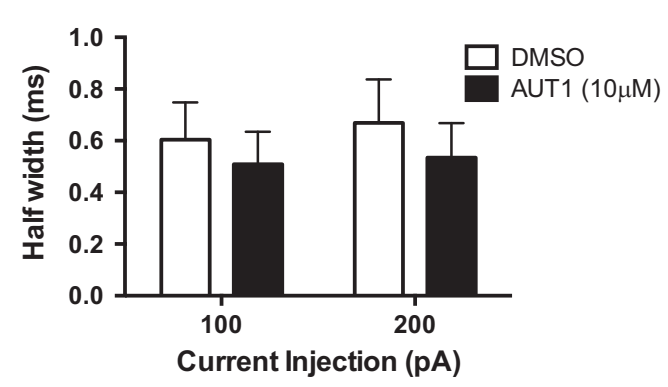

h

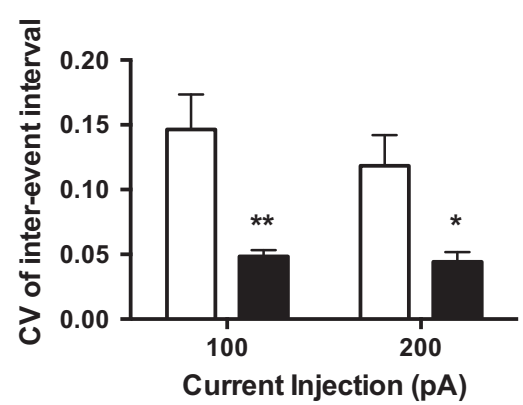

b
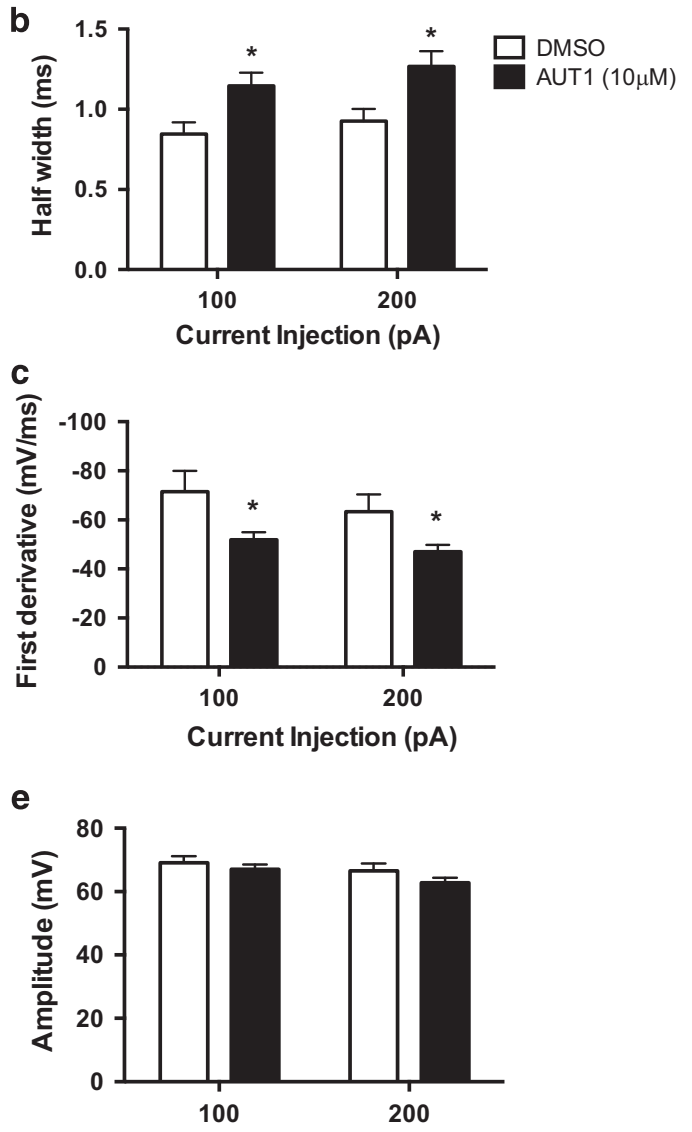

Current Injection (pA)
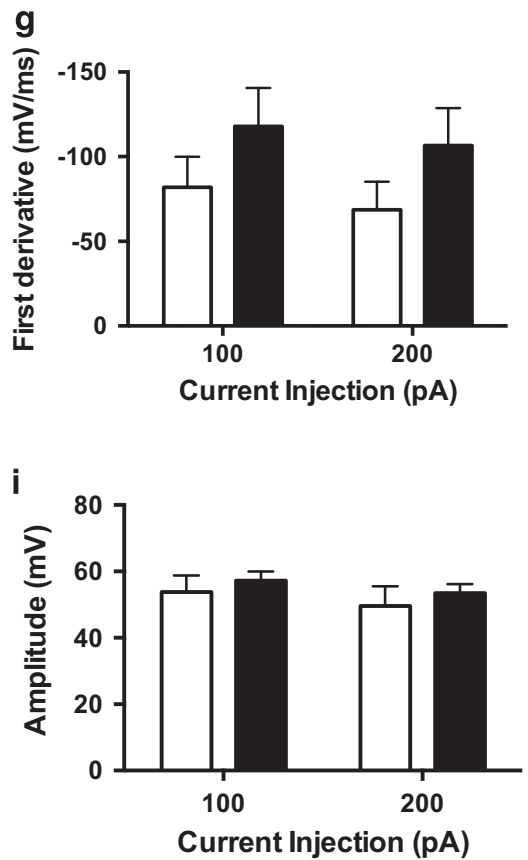

Figure 5 AUTI modulates action potential properties of Clock 19 dopamine and GABAergic neurons. (a) Representative spike trains and individual action potentials from DMSO- and AUTI-treated DA neurons. Middle APs were chosen for analysis of half width, first derivative negative phase amplitude, and spike amplitude. (b) Application of AUTI increased the AP half width of DA neurons at 100 and 200 pA. (c) The first derivative of APs was significantly decreased by AUTI at both 100 and 200 pA current steps. (d) AUTI incubation increased the CV of the interevent interval. (e) Finally, we did not identify an effect of AUTI on the AP amplitude of DA neurons compared with DMSO. ( $f$ Analysis of AP properties of GABAergic revealed no significant effect of AUTI on AP half width. (g) Similarly, AUTI incubation failed to alter the first derivative compared with DMSO. (h) Clock $\triangle 19$ GABAergic neurons however responded to AUTI application with a significant decrease in the CV of the interevent interval at both current steps. (i) AP amplitude was unaffected by AUTI incubation; $n=||-\mid 8$ DA cells/treatment; $n=4-6$ GABA cells/treatment; $* 00.05, * * p<0.01$. 
$p=0.02$, treatment effect) (Figures $3 \mathrm{a}$ and $\mathrm{b}$ ) and $60 \mathrm{mg} / \mathrm{kg}$ dose (Figures $3 \mathrm{c}$ and $\mathrm{d}$ ), with the higher $60 \mathrm{mg} / \mathrm{kg}$ dose completely reversing hyperactivity to WT levels with a significant main effect of treatment $\left(\mathrm{F}_{(1,25)}=9.023\right.$, $p=0.006)$ and a trend for a main effect of genotype $\left(\mathrm{F}_{(1,25)}=3.84, p=0.062\right)$. Importantly, AUT1 did not affect locomotion in WT controls at these doses.

\section{AUT1 Differentially Modulates Clocks19 VTA Neuronal Activity}

Given the effect of AUT1 in attenuating hyperactivity in Clock $\Delta 19$ mice, we focused on the VTA as a region of interest to further explore the underlying mechanism. In an ex vivo preparation, we tested the ability of AUT1 to modulate firing and AP properties of Clock $\Delta 19$ dopamine and nondopamine (putatively GABAergic) neurons (Figures 4 and 5). The identity of cell types was confirmed by standard electrophysiological signatures including morphology, spontaneous firing rate, and the presence of an HCN channel-mediated hyperpolarization-activated current $\left(\mathrm{I}_{\mathrm{h}}\right.$ ) (Figures $4 \mathrm{a}$ and $\mathrm{b}$ ). As measured by whole-cell current clamp, AUT1 bath application $(10 \mu \mathrm{M})$ significantly decreased DA neuron AP firing compared with DMSO (0.1\%) specifically at higher current injections $\left(\mathrm{F}_{(1,31)}=4.049\right.$, $p=0.0530$ treatment effect; $\mathrm{F}_{(10,310)}=392.5, p<0.0001$ current effect; $\mathrm{F}_{(10,310)}=2.994, \quad p=0.0013$ interaction) (Figure 4c). AUT1 appeared to increase the rate of firing in non-DA neurons, but this effect did not reach significance $\left(\mathrm{F}_{(1,10)}=0.5848, p=0.4621\right.$ treatment effect; $\mathrm{F}_{(10,100)}=179.3$, $p<0.0001$ current effect; Figure 4d). Furthermore, we examined the effects of AUT1 application on several action potential properties of DA and non-DA neurons in Clock $\Delta 19$ VTA. We analyzed the half width, amplitude of the negative phase of the first derivative, coefficient of variation (CV) of the interevent interval and amplitude of spikes at 100 and 200 pA current steps (Figure 5a). Here we found that AP half width of Clock $\Delta 19$ mutant DA cells was significantly increased $\left(\mathrm{F}_{(1,27)}=6.306, \quad p=0.0183\right.$ treatment effect; $\mathrm{F}_{(1,27)}=43.05, p<0.0001$ current effect) as was the $\mathrm{CV}$ $\left(\mathrm{F}_{(1,26)}=7.520, p=0.0109\right.$ treatment effect; $\mathrm{F}_{(1,26)}=40.11$, $p<0.0001$ current effect). The first derivative was significantly reduced in the presence of AUT1 $\left(\mathrm{F}_{(1,27)}=6.602\right.$, $p=0.0160$ treatment effect; $\mathrm{F}_{(1,27)}=46.98, p<0.0001$ current effect). AP amplitude remained unchanged $\left(\mathrm{F}_{(1,26)}=1.254\right.$, $p=0.2730$ treatment effect; $\mathrm{F}_{(1,26)}=66.24, p<0.0001$ current effect) (Figures 5b-e). These data indicate that AUT1 broadens individual APs, decreases the rate of repolarization, and increases irregularity of APs within the spike train. When we recorded from putative GABAergic neurons, we did not find significant changes in AP half width $\left(\mathrm{F}_{(1,7)}=0.2994, p=0.6013\right.$ treatment effect; $\mathrm{F}_{(1,7)}=6.060$, $p=0.0434$ current effect), first derivative $\left(\mathrm{F}_{(1,7)}=1.773\right.$, $p=0.2248$ treatment effect; $\mathrm{F}_{(1,7)}=185.5, p<0.0001$ current effect $)$ and amplitude $\left(\mathrm{F}_{(1,7)}=0.3100, \quad p=0.5950\right.$ treatment effect; $F_{(1,7)}=23.30, p=0.0019$ current effect). However, AUT1 significantly decreased the CV at both current steps $\left(\mathrm{F}_{(1,7)}=10.44, p=0.0144\right.$ treatment effect; $\mathrm{F}_{(1,7)}=1.809, \quad p=0.2206$ current effect; Figures $\left.5 \mathrm{f}-\mathrm{i}\right)$. Interestingly, AUT1 did not affect the firing rate of WT DA neurons $\left(\mathrm{F}_{(1,231)}=1.629, p=0.2031\right.$ treatment effect; $F_{(10,231)}=68.90, \quad p<0.0001 \quad$ current effect;
Supplementary Figure S4a). AP properties in WT DA neurons were also unchanged with AUT1 application: half width $\quad\left(\mathrm{F}_{(1,38)}=1.940, \quad p=0.1717\right.$ treatment effect; $\mathrm{F}_{(1,38)}=0.4480, p=0.5073$ current effect); first derivative $\left(\mathrm{F}_{(1,38)}=0.2232, p=0.6393\right.$ treatment effect; $\mathrm{F}_{(1,38)}=0.5129$, $p=0.4783$ current effect); $\mathrm{CV}\left(\mathrm{F}_{(1,38)}=3.543, p=0.0675\right.$ treatment effect; $\mathrm{F}_{(1,38)}=0.03446, p=0.8537$ current effect); and amplitude $\left(\mathrm{F}_{(1,38)}=1.123, p=0.2959\right.$ treatment effect; $\mathrm{F}_{(1,38)}=1.416, \quad p=0.2414$ current effect; Supplementary Figures S4b-e). Together, our results suggest that AUT1 may exert its effects on reducing Clock $\Delta 19$ hyperactivity through a subtle augmentation of GABAergic neuronal firing properties that may lead to an inhibition of DA neuronal firing and spike fidelity.

\section{AUT1 Treatment Does Not Alter Kv3.1 Protein Levels in the VTA}

Immunohistochemistry confirmed the presence of $\mathrm{Kv} 3.1 \mathrm{~b}$ channels in various dopaminergic-rich regions of the brain, including the caudate putamen, Islands of Calleja, VTA, and substantia nigra (Supplementary Figures S5a-d). Based on previous work demonstrating the importance of the mesolimbic system and, in particular, the VTA to manicrelated behaviors in Clock $\Delta 19$ mutant mice (Coque et al, 2011; Dzirasa et al, 2010; McClung et al, 2005; Mukherjee et al, 2010), we used western blotting to quantitate levels of $\mathrm{Kv} 3.1 \mathrm{~b}$ protein (an alternative splice form of the Kv3.1 subunit) specifically in the VTA $1 \mathrm{~h}$ following oral administration of saline or AUT1 $(60 \mathrm{mg} / \mathrm{kg})$. Analysis revealed no significant differences in basal levels of Kv3.1b channel protein in the VTA of Clock $\Delta 19$ mutant mice compared with WT controls and no effect of AUT1 treatment on protein levels $\quad\left(\mathrm{F}_{(1,12)}=2.938, \quad p=0.1122\right.$ genotype effect; $\mathrm{F}_{(1,12)}=3.853, p=0.0733$ treatment effect; $\mathrm{F}_{(1,12)}=4.533$, $p=0.546$ interaction). Interestingly, post hoc analysis revealed a trend-level difference between Kv3.1b levels in WT and mutant VTA with saline treatment $(p=0.1122$; Supplementary Figure S5e).

\section{DISCUSSION}

The current study tested the efficacy of a novel modulator of Kv3-family voltage-gated potassium channels (AUT1) in two separate animal models associated with imbalance of the mesolimbic system: the amphetamine-induced hyperactivity model and the Clock $\Delta 19$ mutant mouse model of mania. Furthermore, Kv3.1-null mice were used to test for behavioral abnormalities in mice lacking Kv3.1 channels. Kv3.1-null mice were found to exhibit both reduced anxiety and reduced depressive-like behaviors, combined with hyperactivity. A similar behavioral phenotype is present in the Clock $\Delta 19$ model of mania, though we have not yet determined whether Kv3.1-null mice share other features of mania including increases in the reward value for drugs of abuse, motivated behavior, and impulsivity. The current findings extend previous studies that have also shown similar behavioral abnormalities in Kv3.1 knockout mice, most notably hyperactivity (Espinosa et al, 2004; Joho et al, 2006). It should be noted that these mice also have highly disrupted daily activity rhythms (Kudo et al, 2011), with increased 
activity during the day (light cycle) and reduced sleep time, similar to that seen in Clock $\Delta 19$ mice and human manic patients (Espinosa et al, 2004; Joho et al, 2006; Naylor et al, 2000).

In the amphetamine-induced hyperactivity model, we found that AUT1 successfully prevented hyperactivity in outbred mice. Importantly, AUT1 was unable to prevent amphetamine-induced hyperactivity in Kv3.1-null mice, demonstrating the importance of Kv3.1 channels to AUT1 mechanism of action. Notably, this effect was specific to Kv3.1 channels, as AUT1 successfully prevented hyperactivity in mice lacking Kv3.2 channels. In addition, AUT1 also reversed hyperactivity in the Clock $\Delta 19$ mutant mouse model of mania, where we found a trend toward a decrease in protein levels of the Kv3.1b channel in the VTA. Based on the manic-like behavioral profile observed in mice lacking functional Kv3.1 channels, one could expect a decrease in Kv3 channels within this midbrain region in mutants. AUT1 did not alter the protein concentration, suggesting that although acute administration of the compound normalizes hyperactivity, the mechanism of action is not mediated by an upregulation of Kv3.1 protein. Together, the current results suggest an association between Kv3.1 channels and maniarelated behaviors possibly through a mechanism involving dopaminergic neural activity. Indeed, given that previous studies have shown that Kv3.1 channels are present in dopaminergic-rich CNS regions and given that we found evidence of protein expression in various dopamine-rich areas, it is likely that Kv3.1 channels indirectly contribute to dopaminergic neural activity through modulation of GABAergic interneuron activity. With regard to the current findings, it should be noted that $30 \%$ of VTA neurons are GABAergic (Sesack and Grace, 2010).

Rosato-Siri et al (2015) have demonstrated AUT1-induced modulation of PV interneuron firing in the somatosensory cortex of mice when potassium channel activity is pharmacologically impaired. Our results showed significant effects of AUT1 on the AP characteristics of Clock $\Delta 19 \mathrm{DA}$ and putative GABAergic neurons in the VTA. The most robust effect of the drug was to reduce the CV of firing of GABAergic neurons. This effect may be associated with the reduced AP half-width and increased rate of repolarization that was observed following AUT1 application; these parameters showed only a trend toward reduction and increase, respectively. However, AP half-width and rate of repolarization before AUT1 application were already very short and fast, respectively, and thus further positive modulation would be limited by other ion channel mechanisms. The combination of effects of AUT1 observed in GABAergic neurons is entirely consistent with Kv3.1-positive modulation. We suggest that observed effects of AUT1 on the AP characteristics of the recorded DA neurons may be secondary to alterations in the firing properties of the GABAergic neurons that synapse onto them. This would be consistent with abundant expression of Kv3.1 channels on GABAergic neurons, but not DA neurons, that has been demonstrated in the substantia nigra pars reticulata (SNr) (Ding et al, 2011; Zhou and Lee, 2011). However, we cannot exclude the possibility that the significant changes in DA cell AP characteristics seen with AUT1 might be because of action of the drug on other ion channels expressed by DA cells. Interestingly, in WT DA cells, we failed to find any effect of AUT1 on firing rate or AP parameters. This is consistent with findings from Rosato-Siri et al (2015) in which AUT1 administration concurrent with TEA incubation restored neuronal excitability of somatosensory interneurons, but AUT1 incubation alone did not differ from control.

A critical aspect of this study was the ability to compare concentrations of AUT1 that were active in vivo with those concentrations that have been shown to modulate Kv3 channels. In vitro, concentrations in the range of $1-10 \mu \mathrm{M}$ were found to modulate Kv3.1 and Kv3.2 channels. In the present study, we found that doses of 30 and $60 \mathrm{mg} / \mathrm{kg}$ of AUT1 produced significant effects on behavior in the mouse models tested. These oral doses were associated with free brain concentrations in the range of $1-2 \mu \mathrm{M}$ over the time course of behavioral testing. These concentrations are therefore consistent with effects mediated by Kv3 channels.

A recent study confirmed the importance of $\mathrm{Kv} 3.1$ channels to additional psychiatric disorders. Levels of Kv3.1 channels were reduced in patients with schizophrenia and normalized with antipsychotic treatment (Yanagi et al, 2014). Here, we focused on the importance of these channels located on cortical parvalbumin (PV) interneurons and the role of these neurons in maintenance of cortical gamma oscillations and synchrony (Sohal et al, 2009) that are disrupted in schizophrenia, bipolar disorder, and in severe cases of unipolar depression (Uhlhaas et al, 2011). A direct role for Kv3.1 channels in the generation of thalamocortical gamma oscillations has been described in the Kv3.1-null mice (Joho et al, 1999), demonstrating a link between Kv3.1 channels and the maintenance of fast spiking neural activity required for gamma synchronization. Moreover, AUT1 was able to restore normal levels of activity of the PV-positive interneurons in the somatosensory cortex (Rosato-Siri et al, 2015). Thus, Kv3.1 channels may play a role in the development of different classes of psychiatric diseases.

As novel medications for psychiatric diseases are greatly needed, we propose that compounds like AUT1, which directly target and modulate Kv3 channels, may be beneficial for the treatment of disorders associated with abnormal neural activity. In particular, this may prove to be a useful strategy for restoring dopaminergic function without the side effects associated with dopamine blockade. Further studies will be needed to understand the exact role these channels play in the development of psychiatric disease.

\section{FUNDING AND DISCLOSURE}

CAM has received honoraria for research presentations from Johnson \& Johnson, Pfizer, Servier, GlaxoSmithKline, Lundbeck, and Sunovion. She is a former consultant for Orphagen Pharmaceuticals and has received compensation. $\mathrm{LB}, \mathrm{RA}, \mathrm{EZ}$, and CM were full-time employees of GlaxoSmithKline at the time these studies were conducted. GSA and CHL are shareholders and full-time employees of Autifony Therapeutics. PKP, MMS, YH, DB-K, and AG declare no conflict of interest.

\section{ACKNOWLEDGMENTS}

We thank Elizabeth Gordon, Heather Buresch, Emily Webster, Mark Brown, and Mariah Hildebrand for assistance with mouse breeding and genotyping. This work was funded 
via a collaborative contract between CAM and GlaxoSmithKline. CAM is also funded by the NIH.

\section{AUTHOR CONTRIBUTIONS}

PKP, MMS, YH, CAM, and CHL participated in research design and wrote or contributed to writing of the manuscript; PKP, MMS, AG, DB-K, LB, RA, EZ, CM, and GSA conducted experiments; PKP, MMS, DBK, LB, RA, GSA, and CHL performed data analysis.

\section{REFERENCES}

Beaulieu JM, Caron MG (2008). Looking at lithium: molecular moods and complex behaviour. Mol Interv 8: 230-241.

Caseras X, Lawrence NS, Murphy K, Wise RG, Phillips ML (2013). Ventral striatum activity in response to reward: differences between bipolar I and II disorders. Am J Psychiatry 170: 533-541. Coque L, Mukherjee S, Cao JL, Spencer S, Marvin M, Falcon E et al (2011). Specific role of VTA dopamine neuronal firing rates and morphology in the reversal of anxiety-related, but not depressionrelated behavior in the ClockDelta19 mouse model of mania. Neuropsychopharmacology 36: 1478-1488.

Ding S, Matta SG, Zhou FM (2011). Kv3-like potassium channels are required for sustained high-frequency firing in basal ganglia output neurons. J Neurophysiol 105: 554-570.

Dzirasa K, Coque L, Sidor MM, Kumar S, Dancy EA, Takahashi JS et al (2010). Lithium ameliorates nucleus accumbens phasesignaling dysfunction in a genetic mouse model of mania. $J$ Neurosci 30: 16314-16323.

Espinosa F, Marks G, Heintz N, Joho RH (2004). Increased motor drive and sleep loss in mice lacking Kv3-type potassium channels. Genes Brain Behav 3: 90-100.

Geddes JR, Miklowitz DJ (2013). Treatment of bipolar disorder. Lancet 381: 1672-1682.

Gonzalez C, Baez-Nieto D, Valencia I, Oyarzun I, Rojas P, Naranjo $\mathrm{D}$ et al (2012). $\mathrm{K}(+)$ channels: function-structural overview. Compr Physiol 2: 2087-2149.

Hernandez-Pineda R, Chow A, Amarillo Y, Moreno H, Saganich M, Vega-Saenz de Miera EC et al (1999). Kv3.1-Kv3.2 channels underlie a high-voltage-activating component of the delayed rectifier $\mathrm{K}+$ current in projecting neurons from the globus pallidus. J Neurophysiol 82: 1512-1528.

Ho CS, Grange RW, Joho RH (1997). Pleiotropic effects of a disrupted $\mathrm{K}+$ channel gene: reduced body weight, impaired motor skill and muscle contraction, but no seizures. Proc Natl Acad Sci USA 94: 1533-1538.

Johnson SW, North RA (1992). Two types of neurone in the rat ventral tegmental area and their synaptic inputs. J Physiol. 450: 455-468.

Joho RH, Ho CS, Marks GA (1999). Increased gamma- and decreased delta-oscillations in a mouse deficient for a potassium channel expressed in fast-spiking interneurons. J Neurophysiol 82: $1855-1864$.

Joho RH, Marks GA, Espinosa F (2006). Kv3 potassium channels control the duration of different arousal states by distinct stochastic and clock-like mechanisms. Eur J Neurosci 23: 1567-1574.

King DP, Vitaterna MH, Chang AM, Dove WF, Pinto LH, Turek FW et al (1997). The mouse clock mutation behaves as an antimorph and maps within the $\mathrm{W}(19 \mathrm{H})$ deletion, distal of kit. Genetics 146: 1049-1060.

Kudo T, Loh DH, Kuljis D, Constance C, Colwell CS (2011). Fast delayed rectifier potassium current: critical for input and output of the circadian system. J Neurosci 31: 2746-2755.

Lenz S, Perney TM, Qin Y, Robbins E, Chesselet MF (1994). GABAergic interneurons of the striatum express the Shaw-like potassium channel Kv3.1. Synapse 18: 55-66.

Lyon M. Animal models for the symptoms of mania. In: Boulton A, Baker G, Martin-Iverson M (eds). Animal Models in Psychiatry, I. Vol 18, Humana Press: New York, NY, 1991, pp 197-244.

Margolis EB, Lock H, Hjelmstad GO, Fields HL (2006). The ventral tegmental area revisited: is there an electrophysiological marker for dopaminergic neurons? J Physiol 577: 907-924.

Martinowich K, Schloesser RJ, Manji HK (2009). Bipolar disorder: from genes to behavior pathways. J Clin Invest 119: 726-736.

McClung CA, Sidiropoulou K, Vitaterna M, Takahashi JS, White FJ, Cooper DC et al (2005). Regulation of dopaminergic transmission and cocaine reward by the Clock gene. Proc Natl Acad Sci USA 102: 9377-9381.

Mukherjee S, Coque L, Cao J-L, Kumar J, Chakravarty S, Asaithamby A et al (2010). Knockdown of clock in the ventral tegmental area through RNA interference results in a mixed state of mania and depression-like behavior. Biol Psychiatry 68: 503-511.

Naylor E, Bergmann BM, Krauski K, Zee PC, Takahashi JS, Vitaterna $\mathrm{MH}$ et al (2000). The circadian clock mutation alters sleep homeostasis in the mouse. J Neurosci 20: 8138-8143.

Phillips ML, Swartz HA (2014). A critical appraisal of neuroimaging studies of bipolar disorder: toward a new conceptualization of underlying neural circuitry and a road map for future research. Am J Psychiatry. 171: 829-843.

Rosato-Siri MD, Zambello E, Mutinelli C, Garbati N, Benedetti R, Aldegheri L et al (2015). A novel modulator of Kv3 potassium channels regulates the firing of parvalbumin-positive cortical interneurons. J Pharmacol Exp Ther 354: 251-260.

Roybal K, Theobold D, Graham A, DiNieri JA, Russo SJ, Krishnan $\mathrm{V}$ et al (2007). Mania-like behavior induced by disruption of CLOCK. Proc Natl Acad Sci USA 104: 6406-6411.

Salvadore G, Quiroz JA, Machado-Vieira R, Henter ID, Manji HK, Zarate CA Jr (2010). The neurobiology of the switch process in bipolar disorder: a review. J Clin Psychiatry 71: 1488-1501.

Sesack SR, Grace AA (2010). Cortico-basal ganglia reward network: microcircuitry. Neuropsychopharmacology 35: 27-47.

Sohal VS, Zhang F, Yizhar O, Deisseroth K (2009). Parvalbumin neurons and gamma rhythms enhance cortical circuit performance. Nature 459: 698-702.

Tohen M, Vieta E (2009). Antipsychotic agents in the treatment of bipolar mania. Bipolar Disord 11(Suppl 2): 45-54.

Uhlhaas PJ, Pipa G, Neuenschwander S, Wibral M, Singer W (2011). A new look at gamma? High- $(>60 \mathrm{~Hz})$ gamma-band activity in cortical networks: function, mechanisms and impairment. Prog Biophys Mol Biol 105: 14-28.

Yanagi M, Joho RH, Southcott SA, Shukla AA, Ghose S, Tamminga CA (2014). Kv3.1-containing $\mathrm{K}(+)$ channels are reduced in untreated schizophrenia and normalized with antipsychotic drugs. Mol Psychiatry 19: 573-579.

Zhou FM, Lee CR (2011). Intrinsic and integrative properties of substantia nigra pars reticulata neurons. Neuroscience 198: 69-94.

Supplementary Information accompanies the paper on the Neuropsychopharmacology website (http://www.nature.com/npp) 